\title{
ONE-STEP SYNTHESIS OF THERMALLY STABLE SOLID MOLYBDENUM BLUE USING BORON PHOSPHATE
}

\author{
P. Ratheshkumar ${ }^{1}$, S. Induja ${ }^{1}$, R. Ravishankar ${ }^{2}$ and P.S. Raghavan ${ }^{1, *}$ \\ ${ }^{1}$ Department of Chemistry, Hindustan Institute of Technology and Science, \\ Padur, Kelambakkam, Chennai-603 103, India \\ ${ }^{2}$ Hindustan Petroleum Corporation Limited, KIADB Industrial Area, Bengaluru-56006 \\ *E-mail: raghavan@hindustanuniv.ac.in
}

\begin{abstract}
For the first time, thermally stable 'molybdenum blue' was prepared in a single step, using boron phosphate. Even though molybdenum blue was discovered more than a century ago, it has not been studied extensively due to its instability. Presence of variable oxidation states of molybdenum makes it more suitable for catalytic transformations, but fewer reports are available, since, they were generally prepared in solutions. The present investigation reports the preparation of stabilized molybdenum blue powder using boron phosphate. The sample was evaluated for its catalytic activity on the transformation of diphenyl sulfide to sulfoxide selectively, and results were compared with $\mathrm{MoO}_{3}$ impregnated analog.
\end{abstract}

Keywords: Molybdenum Blue, $\mathrm{BPO}_{4}$ Stabilized, Polymolybdates, Selective Sulfoxidation.

(C) RASĀYAN. All rights reserved

\section{INTRODUCTION}

Polyoxomolybdates are molecules containing molybdenum in high oxidation state, linked by oxygen atoms forming Keggin type structure ${ }^{1}$. In the presence of hetero atoms like P, Si, As, etc., they form a big-sphere type structure containing $\mathrm{Mo}_{132}$ or big-wheel type structure containing $\mathrm{Mo}_{154}$ or lemon-shaped cluster $\left(\mathrm{Mo}_{368}\right)$. They appear as blue due to partial reduction of $\mathrm{Mo}^{\mathrm{VI}}$ to $\mathrm{Mo}^{\mathrm{V}}$ as first observed by Scheele in $1778^{1,2}$ to be amorphous. The structure of the molybdenum blue allows change of coordination number on side chain at Mo sites and made up of Mo-O-Mo bond with moderate strength containing terminal $\mathrm{Mo}=\mathrm{O}$ sites. In spite of the above said advantages, very less literature is available for exploring catalytic activity of molybdenum blue ${ }^{7}$. Generally, molybdenum blue was prepared by partial reduction of an acidified solution containing molybdates ${ }^{3}$. Other preparation methods include exfoliation of $\mathrm{MoS}_{2}$ nanotube ${ }^{4}$, using reducing agents ${ }^{5}$ and microorganisms ${ }^{6}$. Most of the preparation methods reported in the above literature lead to molybdenum blue solution, where the catalytic applications are limited. Recently, the preparation of solid molybdenum blue powder has been achieved by evaporating the aqueous solution containing the same ${ }^{7}$; another method involved the electrochemical reduction of sodium molybdate solution using graphite/platinum electrodes ${ }^{8}$. The drawbacks of the above process are either they involve high temperature or time-consuming process or not viable for large scale synthesis of solid molybdenum blue.

\section{EXPERIMENTAL}

The preparation of the stabilized molybdenum blue by $\mathrm{BPO}_{4}$ involved mixing of required quantities of boric acid (99.5\%) and ammonium heptamolybdate (99.5\%) thoroughly with the help of mortar-pestle, in presence of $25 \mathrm{ml}$ of 2-propanol. After drying at room temperature, the powder was transferred into a glass beaker and blended well with calculated quantities of phosphoric acid $(85 \%)$ to form a paste. The contents were dried at $120^{\circ} \mathrm{C}$ for $4 \mathrm{~h}$ and the dried mass was powdered and calcined between $150^{\circ} \mathrm{C}$ and $500^{\circ} \mathrm{C}$ for $2 \mathrm{~h}$. The deep-blue colored powder sample was labeled as MB(10)BP (number in parenthesis represents weight \% of $\mathrm{Mo}$ as $\mathrm{MoO}_{3}$ ) and Table- 1 gives the composition and identification of the samples. The appearance of the MB(10)BP is shown in Fig.-1.

The synthesis of the impregnated sample involved mixing boric acid and phosphoric acid in the mole ratio of 1:1 in presence of $25 \mathrm{ml}$ of 2-propanol followed by drying in an oven at $120^{\circ} \mathrm{C}$ for $4 \mathrm{~h}$.

Rasayan J. Chem., 13(2), 803-809(2020)

http://dx.doi.org/10.31788/RJC.2020.1325631

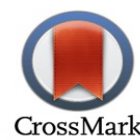


RASĀYAN J. Chem.

Vol. 13 | No. 2 |803 - 809| April - June | 2020

The resultant solid mass was crushed, powdered and calcined between $150^{\circ} \mathrm{C}$ and $500^{\circ} \mathrm{C}$ for $2 \mathrm{~h}$ to form $\mathrm{BPO}_{4}$. In the second step, the calcined $\mathrm{BPO}_{4}$ was powdered and mixed with calculated quantities of ammonium heptamolybdate in presence of $25 \mathrm{ml}$ of 2-propanol. The paste was dried at room temperature and again calcined at $500^{\circ} \mathrm{C}$ for $2 \mathrm{~h}$. The resulting pale green sample was labeled as Mo(10)BP-Imp and the composition is given in Table-1. Similarly, impregnated samples were prepared on silica and alumina support for comparison.

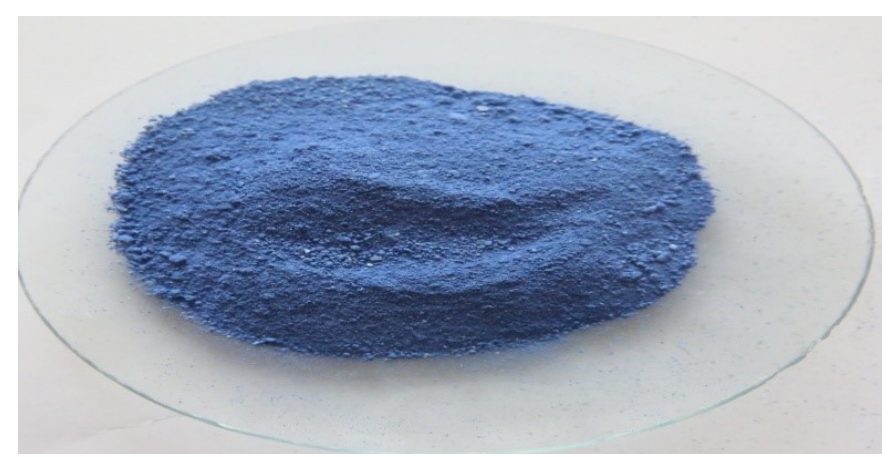

Fig.-1: Appearance of $\mathrm{MB}(10) \mathrm{BP}$ calcined at $500^{\circ} \mathrm{C}$.

Table-1: Composition and Identification of Samples

\begin{tabular}{c|l|c|c|c|c|c|c}
\hline \multirow{2}{*}{ S. No. } & \multirow{2}{*}{ Sample ID } & \multirow{2}{*}{ Color } & \multicolumn{3}{|c|}{ Mole Ratio } & \multicolumn{3}{c}{ Weight \% } \\
\cline { 4 - 8 } & & & $\mathrm{B}_{2} \mathrm{O}_{3}$ & $\mathrm{P}_{2} \mathrm{O}_{5}$ & $\mathrm{As} \mathrm{MoO}_{3}$ & Support & $\mathrm{As} \mathrm{MoO}_{3}$ \\
\hline 1. & $\mathrm{BPO}_{4}$ (support) & White & 0.5 & 0.5 & -- & 100 & -- \\
\hline 2. & $\mathrm{Mo}(10) \mathrm{BP}-\mathrm{Imp}$ & Pale green & 0.5 & 0.5 & 0.08 & 90.2 & 9.8 \\
\hline 3. & $\mathrm{MB}(10) \mathrm{BP}$ & Deep-blue & 0.5 & 0.5 & 0.08 & 90.2 & 9.8 \\
\hline 4. & $\mathrm{MB}(10) \mathrm{BP}(1.1)$ & Deep-blue & 0.5 & 0.55 & 0.08 & 90.8 & 9.2 \\
\hline 5. & $\mathrm{Mo}(10) \mathrm{Al}_{2} \mathrm{O}_{3}$ & Pale green & - & - & 0.08 & 90.1 & 9.9 \\
\hline 6. & $\mathrm{Mo}(10) \mathrm{SiO}_{2}$ & Pale green & - & - & 0.08 & 90.1 & 9.9 \\
\hline
\end{tabular}

The powder X-ray diffraction patterns of all samples were recorded in PANalytical X-PERT3 instrument, with $\mathrm{Cu} \mathrm{K} \mathrm{K}_{\alpha}$ of $1.54 \AA$, continuous scan in the $2 \theta$ range of $5-60^{\circ}$. The Scanning Electron Micrograph was captured using JEOL JSM-7401F instrument and the FTIR spectra were recorded in Perkin Elmer (Model: Spectrum RXi) by forming pellets with $\mathrm{KBr}$. The UV-Visible spectra were recorded in Systronics Type 2202 spectrophotometer.

Oxidation is one of the most fundamental reactions in organic synthesis. The controlled oxidation of sulfides to sulfoxides without forming sulfones, yet remains a challenge. The stabilized molybdenum blue from the present investigation was tested for its catalytic activity for oxidation of diphenylsulfide using hydrogen peroxide as the oxidant.The reaction was conducted in a batch reactor, where, the diphenylsulfide $(98 \%, 50 \mathrm{mg}$ ) was dissolved in a $2 \mathrm{ml}$ of a suitable solvent (methanol or ethanol or 1:1 methanol/dichloromethane). The catalyst was charged $(5 \mathrm{mg})$ under stirring followed by the addition of $28 \mu \mathrm{l}$ hydrogen peroxide $(30 \%)$ at room temperature $\left(27^{\circ} \mathrm{C}-30^{\circ} \mathrm{C}\right)$. The progress of the reaction was monitored using TLC and HPLC.

\section{RESULTS AND DISCUSSION}

In the preparation of stabilized molybdenum blue, the order of adding the components play a vital role. When phosphoric acid was added to a mixture of boric acid and ammonium heptamolybdate, it resulted in the formation of molybdenum blue, while such a phenomenon was not observed when the first phosphoric acid was added to boric acid, followed by addition of ammonium heptamolybdate. Thus, it was inferred that formation of $\mathrm{BPO}_{4}$ and molybdenum blue takes place simultaneously. In the second method of addition, since, all phosphates are consumed for the formation of boron phosphate, free phosphates were not available for the formation of molybdenum blue.

The XRD patterns of boron phosphate calcined at $150^{\circ} \mathrm{C}$ showed distinct peaks corresponding to the formation of $\mathrm{BPO}_{4}$ phase (JCPDS No.74-1169) (Fig.-2). Additional peaks at 2 $\theta=14.5,14.97,28(100 \%)$ 
RASĀYAN J. Chem.

Vol. 13 | No. 2 |803 - 809| April - June | 2020

indicates presence of unreacted boric acid (JCPDS No.73-2158). With the increase in calcination temperature to $350^{\circ} \mathrm{C}$, the peaks corresponding to unreacted boric acid disappeared and on further increasing to $500^{\circ} \mathrm{C}$, pure boron phosphate phase with increased crystallinity was formed. The XRD pattern of molybdenum impregnated sample (Mo(10)BP-imp) showed presence on $\mathrm{MoO}_{3}$ phase (JCPDS PDF No.89-5108) and $\mathrm{BPO}_{4}$ phase. Similarly, the XRD patterns of molybdenum impregnated silica confirmed the formation of $\mathrm{MoO}_{3}$ phase, while that impregnated over alumina (neutral) showed an amorphous phase.

The XRD patterns of $\mathrm{BPO}_{4}$ stabilized molybdenum blue sample $(\mathrm{MB}(10) \mathrm{BP})$ calcined at $150^{\circ} \mathrm{C}$ indicate peaks corresponding to boron phosphate and unreacted boric acid (Fig.-3).The additional peaks corresponding to $2 \theta=9.6,12.19(100 \%)$ can be assigned to unreacted ammonium heptamolybdate (JCPDS No.70-1707) and the peaks at $2 \theta=12.19,14.08$ can be assigned to the presence of $\left(\mathrm{NH}_{4}\right)_{2} \mathrm{Mo}_{2} \mathrm{O}_{7}$ (JCPDS No.70-1706). With the increase in calcination temperature to $350^{\circ} \mathrm{C}$, the intensity of peaks corresponding to unreacted ammonium heptamolybdate and $\left(\mathrm{NH}_{4}\right)_{2} \mathrm{Mo}_{2} \mathrm{O}_{7}$ decreased, while the excess boric acid was converted to $\mathrm{B}_{2} \mathrm{O}_{3}$ confirmed by the peak at $2 \theta=28$ (JCPDS PDF No.06-0297). With the increase in calcination temperature to $500^{\circ} \mathrm{C}$, the crystallinity of $\mathrm{BPO}_{4}$ increased.

The $\mathrm{BPO}_{4}$ phase was formed reacting equimolar ratio of borate and phosphate. When the molybdenum was added in the reaction mixture during the preparation of $\mathrm{MB}(10) \mathrm{BP}$, it reacts with phosphates to form molybdenum blue, leaving excess borate in the mixture. This excess boric acid was converted to $\mathrm{B}_{2} \mathrm{O}_{3}$ at high temperatures, which was reflected in the corresponding XRD pattern (Fig.-3). To verify the inference, a sample was prepared using excess phosphoric acid $\left(\mathrm{B}_{2} \mathrm{O}_{3}: \mathrm{P}_{2} \mathrm{O}_{5}=1: 1.1 ; \mathrm{MB}(10) \mathrm{BP}(1.1)\right)$, which, showed absence of the peak at $2 \theta=28$, exhibiting the presence of pure $\mathrm{BPO}_{4}$ phase. The molybdenum blue was observed to be amorphous as reported by earlier workers. ${ }^{1,2,8}$

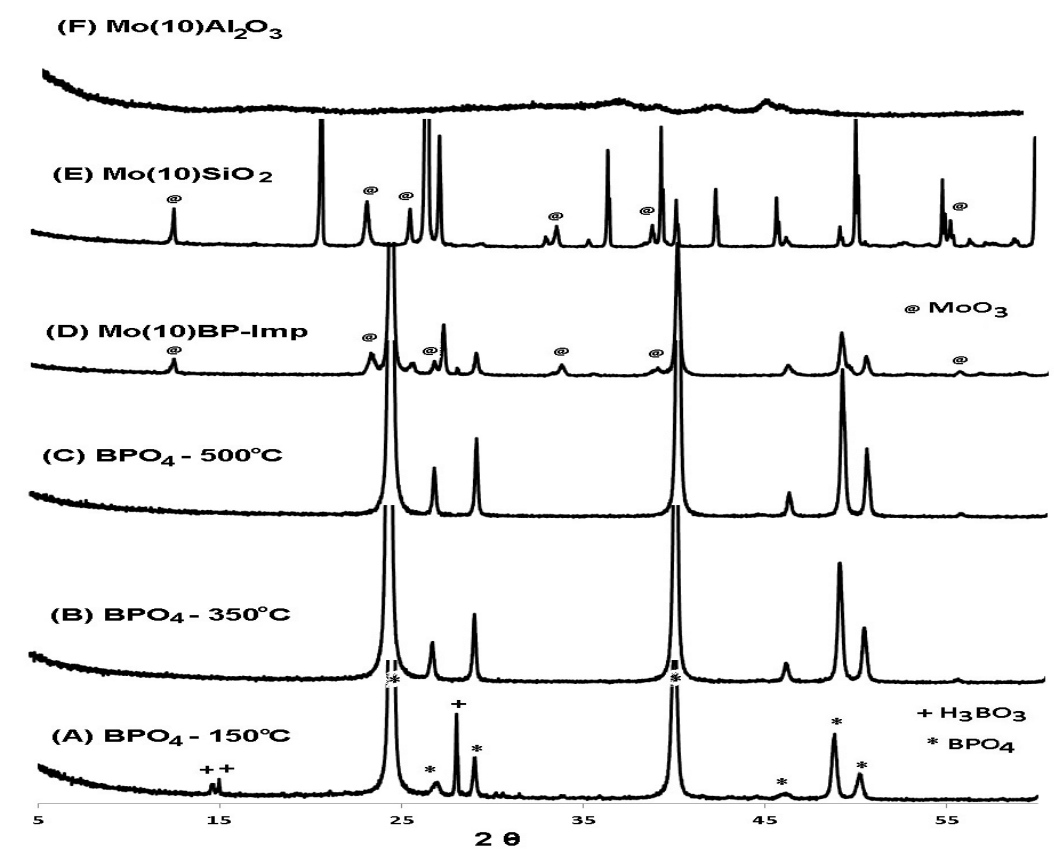

Fig.-2: XRD Patterns of $\mathrm{BPO}_{4}$ calcined at Different Temperatures and $\mathrm{MoO}_{3}$ impregnated on $\mathrm{BPO}_{4}, \mathrm{SiO}_{2}$ and $\mathrm{Al}_{2} \mathrm{O}_{3}$.

The FTIR spectra of $\mathrm{BPO}_{4}$ calcined at $500^{\circ} \mathrm{C}$ (Fig.-4) exhibited O-B-O bending vibration at $550 \mathrm{~cm}^{-1}$ and tetrahedral B-O symmetrical stretching at $600 \mathrm{~cm}^{-1}$. The asymmetric tetrahedral B-O stretching was observed at $900 \mathrm{~cm}^{-1}$. The $\mathrm{MB}(10) \mathrm{BP}$ calcined at $150^{\circ} \mathrm{C}$ showed additional absorption (other than $\mathrm{BPO}_{4}$ ) at $709 \mathrm{~cm}^{-1}$ due to $v-\mathrm{Mo}-\mathrm{O}$ vibration and Mo-O-Mo vibration at $885 \mathrm{~cm}^{-1}$ corresponding to $\mathrm{Mo}^{6+}$ species ${ }^{10}$. The residual $\mathrm{NH}_{4}^{+}$showed vibration ${ }^{11}$ at $3173 \mathrm{~cm}^{-1}$ and $1400 \mathrm{~cm}^{-1}$. The intensity of these peaks decreased on increasing the calcination temperature to $500^{\circ} \mathrm{C}$ due to the decomposition of ammonium species. 
RASĀYAN J. Chem.

Vol. 13 | No. 2 |803-809| April - June | 2020

The SEM of $\mathrm{BPO}_{4}$ (Fig.-5A) shows flower-like morphology, having clusters of the size $1.5-2$ microns, made of boron phosphate plates of the size around $100 \mathrm{~nm} \times 300 \mathrm{~nm}$. The morphology of the MB(10)BP (Fig.-5B) was completely different from that of $\mathrm{BPO}_{4}$ and showed agglomerates of the size $500 \mathrm{~nm}$, containing nanoparticles of molybdenum species.

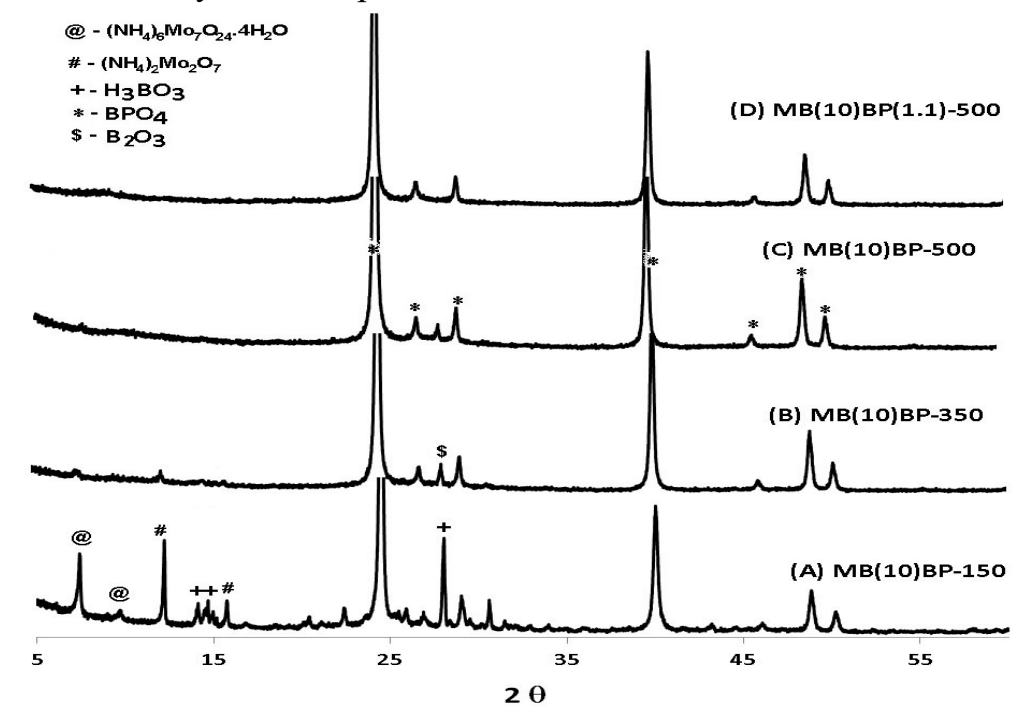

Fig.-3: XRD patterns of Molybdenum Blue (MB(10)BP) calcined at $150^{\circ} \mathrm{C}, 350^{\circ} \mathrm{C}$ and $500^{\circ} \mathrm{C} ; \mathrm{MB}(10) \mathrm{BP}(1.1)$.

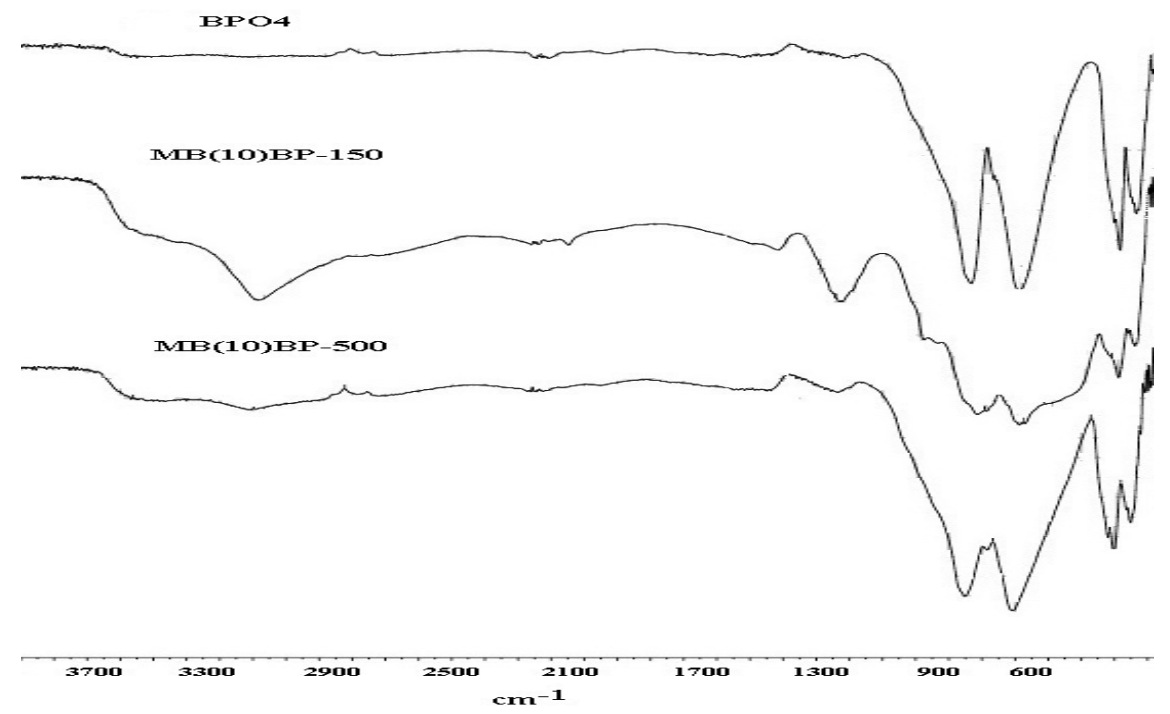

Fig.-4: FTIR Spectra of Boron Phosphate calcined at $500^{\circ} \mathrm{C}$; $\mathrm{BPO}_{4}$ stabilized Molybdenum Blue calcined at $150^{\circ} \mathrm{C}$ and $500^{\circ} \mathrm{C}$

The UV-visible spectra of the samples are shown in the Fig.-6. The $\mathrm{BPO}_{4}$ did not show any characteristic absorption, while the $\mathrm{MB}(10) \mathrm{BP}$ showed absorption at $600 \mathrm{~nm}$ and $\mathrm{MB}(10) \mathrm{BP}(1.1)$ showed absorption at $610 \mathrm{~nm}$ as reported by earlier workers ${ }^{8}$.

The transformations of sulfides to sulfoxides over different catalysts were studied and the results are presented in Fig.-7. The blank support did not show any appreciable activity, while $\mathrm{MoO}_{3}$ impregnated silica showed better activity and that impregnated over alumina and $\mathrm{BPO}_{4}$ exhibited considerable activities. A maximum conversion of around $80 \%$ was observed at $120 \mathrm{~min}$ of reaction time. The $\mathrm{MB}(10) \mathrm{BP}$ catalyst showed nearly $85 \%$ conversion within $30 \mathrm{~min}$ of reaction time and reached $90 \%$ conversion at $60 \mathrm{~min}$.

The MB(10)BP calcined at different temperatures were tested for their catalytic activities and the results are presented in Fig.-8. 
RASĀYAN J. Chem.

Vol. 13 | No. 2 |803- 809| April - June | 2020
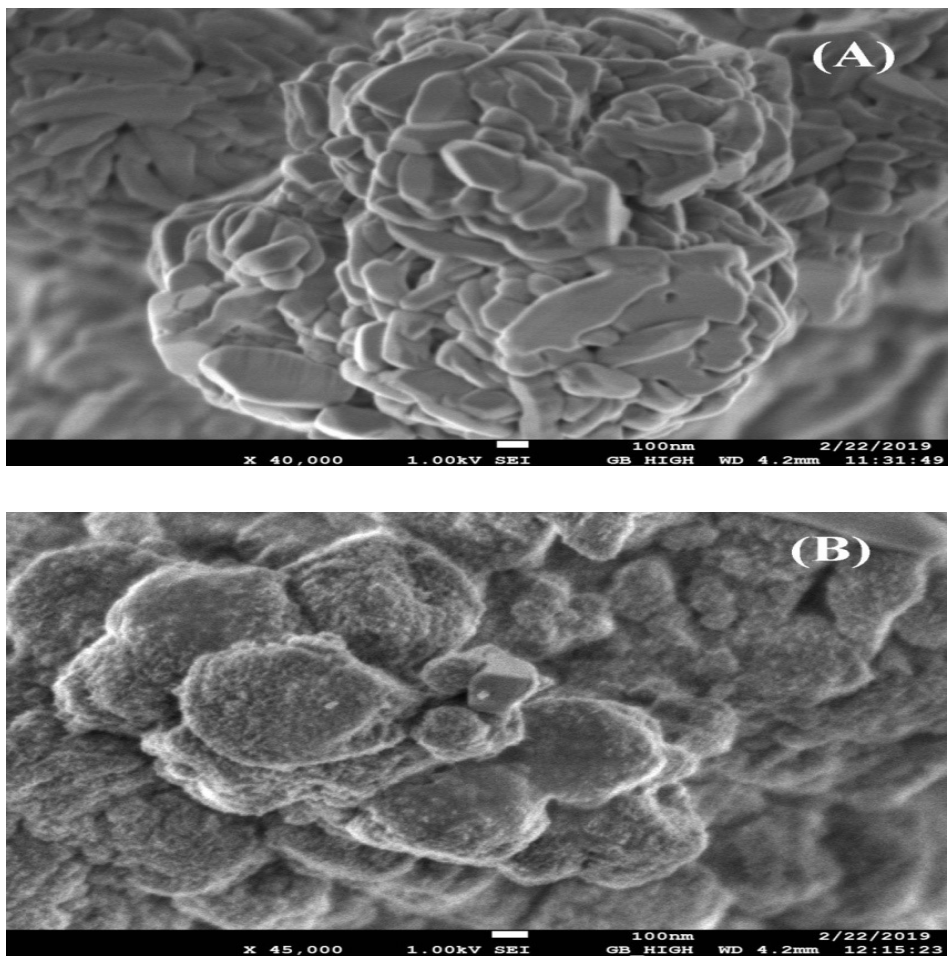

Fig.-5: SEM ImageS of (A) $\mathrm{BPO}_{4}$ and (B) MB(10)BP-500 Samples

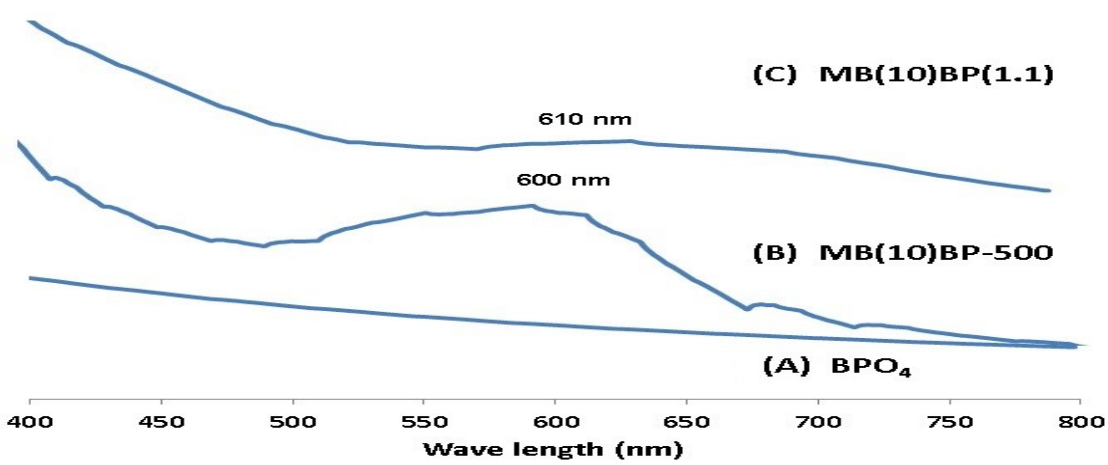

Fig.-6: UV-Visible Spectra of $\mathrm{BPO}_{4}, \mathrm{MB}(10) \mathrm{BP}$ and $\mathrm{MB}(10) \mathrm{BP}(1.1)$ Samples

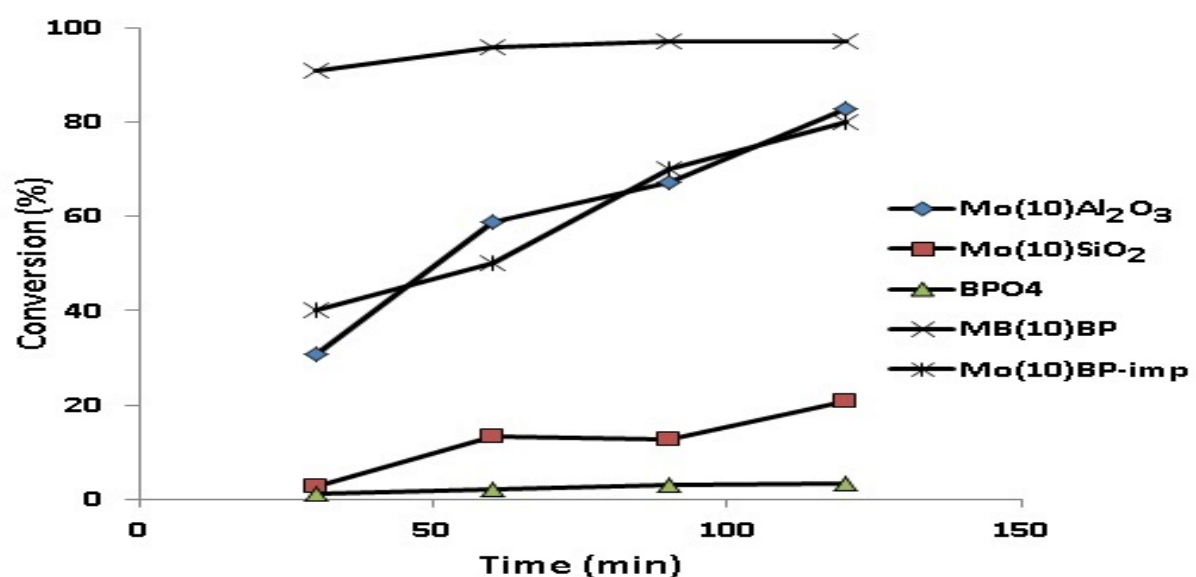

Fig.-7: Oxidation of Diphenylsulfide to Diphenylsulfoxide Over Different Catalysts.

807 
RASĀYAN J. Chem.

Vol. 13 | No. 2 |803 - 809| April - June | 2020

The initial activities of the catalysts were found to increase with calcination temperature but attained equilibrium activity after $60 \mathrm{~min}$ of reaction time. The $\mathrm{MB}(10) \mathrm{BP}(1.1)$ catalyst exhibited very high activity of around $97 \%$ within 30 min of reaction time and the reactants were not detected in the reaction mixture after $35 \mathrm{~min}$.

Table- 2 compares the activities of the catalysts and that reported in the literature by earlier workers. The TON was calculate assuming all molybdenum species in the sample are participating in the reaction. The $\mathrm{MoO}_{3}$ impregnated $\mathrm{BPO}_{4}$ and $\mathrm{Al}_{2} \mathrm{O}_{3}$ exhibited TON of 28 and 21, respectively, with the formation of sulfones. The MB(10)BP showed TON of 67 and that of $\mathrm{MB}(10) \mathrm{BP}(1.1)$ was calculated to be 69 .

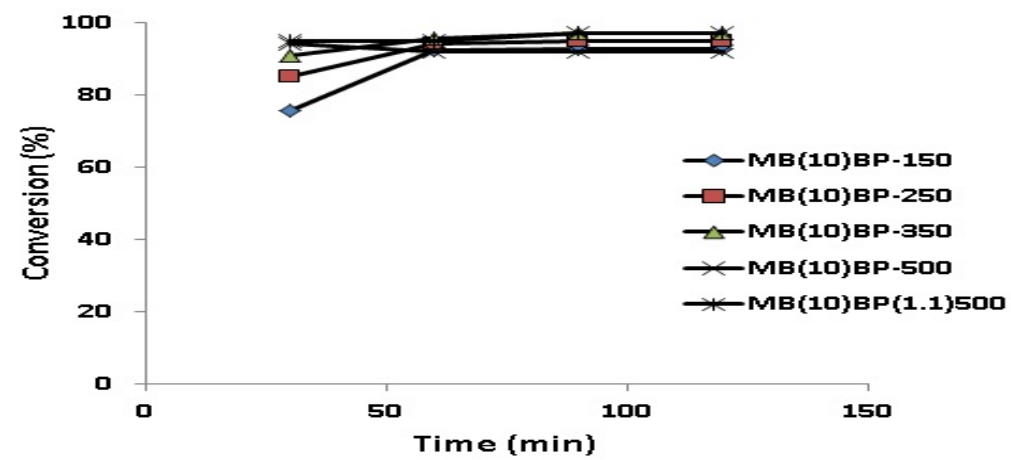

Fig.-8: Oxidation of Diphenylsulfide to Diphenylsulfoxide over MB(10)BP Catalysts calcined at Different Temperatures.

Earlier workers have reported nearly $100 \%$ conversion of sulphides, but the quantity of catalyst used was quite high (TON - 0.55 and 1). The Mojtaba Bagherzadeh et al. has reported $98 \%$ conversion of sulfides and formation of $2 \%$ sulfones with relatively less equivalence of catalyst (TON-28), but reaction time was $120 \min ^{14}$.

The influence of catalyst content (MB(10)BP-500) over the conversion of sulfide was studied in the range $1 \mathrm{mg}$ to $5 \mathrm{mg}$ for $50 \mathrm{mg}$ of the substrate with $28 \mu \mathrm{l}$ of oxidant $\left(\mathrm{H}_{2} \mathrm{O}_{2}\right)$ at room temperature (Fig.-9). The reaction reached maximum conversion with $2 \mathrm{mg}$ of the catalyst at a reaction time of around $30 \mathrm{~min}$.

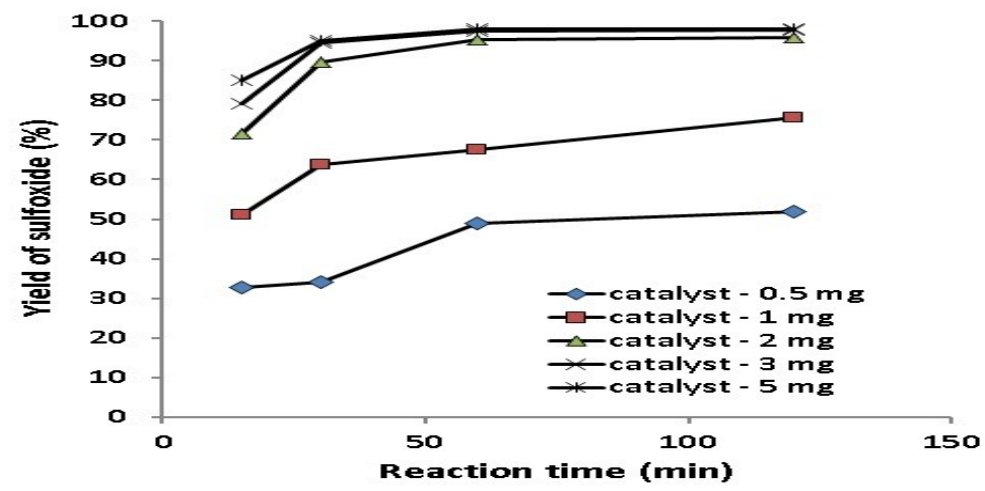

Fig.-9: Influence of Catalyst (MB(10)BP-500) Content on Oxidation of Sulfide.

Table-2: Catalytic Transformation of Diphenylsulfide over Different Catalysts at Room Temperature

\begin{tabular}{|c|c|c|c|c|c|c|c|c|}
\hline$\frac{\vec{\pi}}{\underset{\pi}{\tilde{E}}}$ & 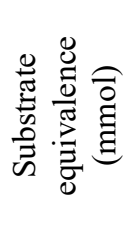 & 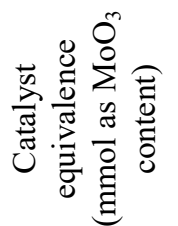 & 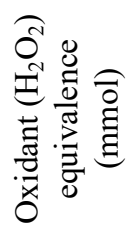 & $\begin{array}{l}\stackrel{\overbrace \Xi}{\Xi} \\
\stackrel{\Xi}{\Xi} \\
\stackrel{\Xi}{\Xi}\end{array}$ & $\stackrel{*}{\text { Z }}$ & 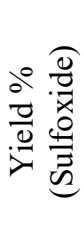 & 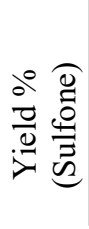 & 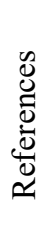 \\
\hline Мo(10)BP-imp & 1 & 0.014 & 1 & 30 & 28 & 40 & 5 & - \\
\hline $\mathrm{MB}(10) \mathrm{BP}$ & 1 & 0.014 & 1 & 30 & 67 & 94 & - & - \\
\hline
\end{tabular}


RASĀYAN J. Chem.

Vol. 13 | No. 2 |803 - 809| April - June | 2020

\begin{tabular}{l|c|c|c|c|c|c|c|c}
\hline $\mathrm{MB}(10) \mathrm{BP}(1.1)$ & 1 & 0.014 & 1 & 30 & 69 & 98 & - & - \\
\hline $\mathrm{Mo}(10) \mathrm{Al}_{2} \mathrm{O}_{3}$ & 1 & 0.014 & 1 & 30 & 21 & 30 & 9 & - \\
\hline $\mathrm{Mo}(10) \mathrm{SiO}_{2}$ & 1 & 0.014 & 1 & 30 & 2 & 3 & - & - \\
\hline $\mathrm{Fe}_{3} \mathrm{O}_{4} @ \mathrm{SiO}_{2}-\mathrm{NH}_{2}-\mathrm{Mo}$ & 1 & 1.8 & 1.1 & 30 & 0.55 & 99 & - & 12 \\
\hline $\mathrm{CpMoO}_{2} \mathrm{Cl}$ & 1 & 1.0 & 1 & 15 & 1 & 99 & - & 13 \\
\hline Schiff's Base complex & 1 & 0.035 & 1 & 120 & 28 & 98 & 2 & 14 \\
\hline
\end{tabular}

*TON calculated assuming that all molybdenum is involved in the reaction.

\section{CONCLUSION}

Solid molybdenum blue powder stabilized with $\mathrm{BPO}_{4}$ has been prepared by a simple one-step synthesis procedure. The XRD analysis proved that the $\mathrm{MB}(10) \mathrm{BP}$ was thermally stable upto $500^{\circ} \mathrm{C}$ containing $\mathrm{BPO}_{4}$ phase, while molybdenum blue was found to be amorphous. The FTIR spectra of MB(10)BP showed vibrations of molybdenum corresponding to polymolybdates. The SEM image showed agglomerates of molybdenum blue nanoparticles. The present sample (MB(10)BP(1.1)) exhibited a high yield of nearly 97\% sulfoxide, without forming sulfones within 30 minutes of the reaction time. On the other hand, the $\mathrm{MoO}_{3}$ impregnated $\mathrm{BPO}_{4}$ (Mo(10)BP-Imp) exhibited $40 \%$ selectivity of sulfoxide after 30 minutes of the reaction time, while the $\mathrm{BPO}_{4}$ exhibited negligible reactivity.

\section{REFERENCES}

1. A. Müller, S. Roy, Coordination Chemistry Reviews, 245, 153(2003), DOI:10.1016/S00108545(03)00110-3.

2. A. Müller, J. Meyer, E. Krickemeyer and E. Diemann, Angewandte Chemie International Edition, 35, 1206(1996), DOI:10.1002/anie.199612061.

3. Ippei Nakamura, Haralampos N. Miras, Aya Fujiwara, Masaru Fujibayashi, Yu-Fei Song, Leroy Cronin and Ryo Tsunashima, Journal of American Chemical Society, 137, 6524(2015),DOI: $10.1021 / \mathrm{ja} 512758 \mathrm{j}$.

4. M. KlanjsekGunde, J. Kovaca, I. Iskra, J. Jelenca, M.Remskara, Material Research Bulletin, 48(2), 802 (2013), DOI: 10.1016/j.materresbull.2012.11.062.

5. José Escobar, María C.Barrera, Ana W.Gutiérrez, María A. Cortés-Jacome, Carlos Angeles-Chávez, José A.Toledo, Dora A.Solís-Casados, Applied Catalysis B: Environmental, 237, 708(2018), DOI:10.1016/j.apcatb.2018.06.034.

6. Yunus Shukor, Hamzah Adam, Khalid Ithnin, Ibrahim Yunus, Nor Aripin Shamaan and Mohd. Arif Syed, Journal of Biosciences, 7, 1448(2007), DOI:10.3923/jbs.2007.1448.1452.

7. Xi Liu, Marco Conte, WeihaoWeng, Qian He, Robert L. Jenkins, Masashi Watanabe, David J. Morgan, David W. Knight, Damien M. Murphy, Keith Whiston, Christopher J. Kiely and Graham J. Hutchings, Catalysis Science \& Technology, 5, 217(2015), DOI:10.1039/c4cy01213e.

8. Ozge Koyun, Semih Gorduk, Melih Besir Arvas, Yucel Sahin, Synthetic Metals, 233, 111(2017), DOI: 10.1016/j.synthmet.2017.09.009.

9. M. Mamlouk, K. Scott, Journal of Power Sources, 286, 290(2015), DOI:10.1016/j.jpowsour.2015.03.169.

10. Tzu Hsuan Chiang and Hung Che Yeh, Materials, 6, 4609(2013), DOI:10.3390/ma6104609.

11. Jia Li, Fung-luen Kwong, Dickon H. L. Ng, Journal of American Ceramic Society, 91, 1350(2008), DOI: $10.1111 / \mathrm{j} .1551-2916.2008 .02276 . x$.

12. Yasuhiro Uozumi, Makoto Nagaosa, Synfacts, 11, 1117(2015), DOI:10.1055/s-0035-1560283.

13. Carla A. Gamelas, Tiago Lourenço, andré Pontes da Costa, Ana L. Simplício, Beatriz Royo, Carlos C. Romão, Tetrahedron Letters, 49, 4708(2008), DOI:10.1016/j.tetlet.2008.05.126.

14. Mojtaba Bagherzadeh, Hooman Karimi and Mojtaba Amini, Journal of Coordination Chemistry, 70, 2986(2017), DOI: 10.1080/00958972.2017.1383603

[RJC-5631/2019] 